\title{
Assessment of radiographic and clinical outcomes of an articulating expandable interbody cage in minimally invasive transforaminal lumbar interbody fusion for spondylolisthesis
}

\author{
Lara W. Massie, MD, ${ }^{1}$ Hesham Mostafa Zakaria, MD,, Lonni R. Schultz, PhD, ${ }^{1}$ Azam Basheer, MD, ${ }^{1}$ \\ Morenikeji Ayodele Buraimoh, MD, ${ }^{3}$ and Victor Chang, MD ${ }^{1}$
}

Departments of ${ }^{1}$ Neurosurgery and ${ }^{2}$ Public Health Sciences, Henry Ford Health System, Detroit, Michigan; and ${ }^{3}$ Department of Orthopedics, University of Maryland, Baltimore, Maryland

OBJECTIVE The inability to significantly improve sagittal parameters has been a limitation of minimally invasive surgery for transforaminal lumbar interbody fusion (MIS TLIF). Traditional cages have a limited capacity to restore lordosis. This study evaluates the use of a crescent-shaped articulating expandable cage (Altera) for MIS TLIF.

METHODS This is a retrospective review of 1- and 2-level MIS TLIF. Radiographic outcomes included differences in segmental and lumbar lordosis, disc height, evidence of fusion, and any endplate violations. Clinical outcomes included the numeric rating scale for leg and back pain and the Oswestry Disability Index (ODI) for low-back pain.

RESULTS Thirty-nine patients underwent single-level MIS TLIF, and 5 underwent 2-level MIS TLIF. The mean age was 63.1 years, with $64 \%$ women. On average, spondylolisthesis was corrected by $4.3 \mathrm{~mm}$ (preoperative $=6.69 \mathrm{~mm}$, postoperative $=2.39 \mathrm{~mm}, p<0.001$ ), the segmental angle was improved by $4.94^{\circ}$ (preoperative $=5.63^{\circ}$, postoperative $=10.58^{\circ}$, $p<0.001$ ), and segmental height increased by $3.1 \mathrm{~mm}$ (preoperative $=5.09 \mathrm{~mm}$, postoperative $=8.19 \mathrm{~mm}, \mathrm{p}<0.001$ ). At 90 days after surgery the authors observed the following: a smaller postoperative sagittal vertical axis was associated with larger changes in back pain at 90 days $(r=-0.558, p=0.013)$; a larger decrease in spondylolisthesis was associated with greater improvements in ODI and back pain scores $(r=-0.425, p=0.043$, and $r=-0.43, p=0.031$, respectively); and a larger decrease in pelvic tilt (PT) was associated with greater improvements in back pain $(r=-0.548, p=$ 0.043). For the 1-year PROs, the relationship between the change in PT and changes in ODI and numeric rating scale back pain were significant $(r=0.612, p=0.009$, and $r=-0.803, p=0.001$, respectively) with larger decreases in PT associated with larger improvements in ODI and back pain. Overall for this study there was a $96 \%$ fusion rate.

Fourteen patients were noted to have endplate violation on intraoperative fluoroscopy during placement of the cage. Only 3 of these had progression of their subsidence, with an overall subsidence rate of $6 \%$ (3 of 49 ) visible on postoperative $\mathrm{CT}$.

CONCLUSIONS The use of this expandable, articulating, lordotic, or hyperlordotic interbody cage for MIS TLIF provides a significant restoration of segmental height and segmental lordosis, with associated improvements in sagittal balance parameters. Patients treated with this technique had acceptable levels of fusion and significant reductions in pain and disability.

https://thejns.org/doi/abs/10.3171/2017.10.FOCUS17562

KEY WORDS spondylolisthesis; minimally invasive; TLIF; transforaminal lumbar interbody fusion; lordotic cage

ABBREVIATIONS EBL = estimated blood loss; LL = lumbar lordosis; MIS = minimally invasive surgery; NRS = numeric rating scale; ODI = Oswestry Disability Index; OR = operating room; $\mathrm{PI}=$ pelvic incidence; $\mathrm{PRO}=$ patient-reported outcome; $\mathrm{PT}=$ pelvic tilt; SVA = sagittal vertical axis; TLIF = transforaminal lumbar interbody fusion. SUBMITTED September 1, 2017. ACCEPTED October 25, 2017. INCLUDE WHEN CITING DOI: 10.3171/2017.10.FOCUS17562. 
$\mathrm{S}$ PONDYLOLISTHESIS is a common indication for spine surgery, with clinical evidence that fusion is an effective treatment for this pathology. ${ }^{10,11}$ Transforaminal lumbar interbody fusion (TLIF) has been shown to be an effective surgical procedure for spondylolisthesis, ${ }^{4,9,13,22}$ and there is growing interest in whether minimally invasive surgery for TLIF (MIS TLIF) can provide the same benefits. ${ }^{1,3,16,35}$ Although MIS TLIF is associated with a significant learning curve, increased use of fluoroscopy, and risk of nerve injury, $, 6,626-28,44-47$ its benefits over open TLIF include decreased operating time, decreased intraoperative blood loss, decreased hospital stay, improved cost-effectiveness, faster return to work, and decreased pain. ${ }^{20,24,29,32,37-39,42}$

One controversy with MIS TLIF is the ability to provide adequate reduction of spondylolisthesis and correction of radiographic parameters, or even whether such changes are necessary. $7,8,14,30,33,40$ With a growing body of evidence emphasizing the finding that the restoration and maintenance of spinopelvic parameters after spine surgery is associated with improved outcomes, $, 5,12,17,18,25$, $34,36,41$ there has been interest in applying these principles to MIS TLIF as well. Current product limitations, which include cage footprint size, fixed height of interbody cage, and nonlordotic shape of the implant, have limited the surgeon's armamentarium to achieve these goals by providing inadequate anterior column height restoration through the access corridors of both open and MIS TLIF.

However, several expandable lordotic interbody cages now exist for use in TLIF. One current cage on the market incorporates a crescent shape with articulation and expansion in a lordotic configuration (Altera, Globus Medical), and allows for placement via a transforaminal trajectory (Fig. 1). It is specifically designed to be articulated and positioned horizontally across the anterior column and then expanded to achieve greater height while maintaining a low entry profile (Fig. 2). The cage itself also has a built-in lordotic configuration, again contributing to further lordosis. Of note, the cage material used is primarily titanium alloy. The purpose of this study was to assess the efficacy of this cage in a clinical setting. We hypothesized that this cage design allows for improved restoration of intradiscal height and improved segmental lordosis, while allowing for correction of spondylolisthesis. An additional hypothesis was that patient-reported outcomes (PROs) would be consistent with those of other series published in the literature.

\section{Methods \\ Patient Population}

This study was approved by the Henry Ford Hospital Institutional Review Board. This is a retrospective cohort study using prospectively collected data. In a query of all lumbar interbody fusion cases performed using the Globus Altera cage between November 2014 and December 2016, 58 patients with 98 levels of intervention were identified, with cases ranging from 1 to 4 levels of interbody fusion. For this investigation, our analysis was limited to 1 - and 2-level interventions, totaling 44 patients. One patient with a single-level intervention was excluded because their indication for surgery was discitis.

\section{Clinical and Radiographic Assessment}

Patient demographic data included patient age, sex, and body mass index, and the American Society of Anesthesiologists grade was also collected. Surgical data included number of levels operated on, operating room (OR) time, and estimated blood loss (EBL). For all patients, routine clinical follow-up was done at 6 weeks, 3 months, 6 months, 1 year, and 2 years after surgery. The 36 -inch lateral standing films were obtained preoperatively, 3 months, 6 months, 1 year, and 2 years after surgery. The CT scans were performed at 6 months and 1 year to assess for bony fusion. The PROs were collected preoperatively, 3 months, 1 year, and 2 years after surgery. Primary outcomes included both clinical and radiographic outcome measures. Clinical outcome measures consisted of PROs, and included the Oswestry Disability Index (ODI) for low-back pain and the numeric rating scale (NRS) for low-back and leg pain.

Radiographic analysis included full-length, free-standing anteroposterior and lateral 36-inch spine radiographs as well as CT scans. Standing films were analyzed for sagittal parameters in a standardized fashion by using validated software (Surgimap). ${ }^{19}$ Primary radiographic outcome measures included pelvic incidence (PI), pelvic tilt (PT), lumbar lordosis (LL), PI-LL mismatch, and sagittal vertical axis (SVA). In addition, measurements of the disc height at the posterior vertebral body, segmental angle, and sagittal angle and of the amount of listhesis (measured by the offset of posterior vertebral body wall in millimeters) were also collected. Postoperative CT scanning was done to assess for bony fusion, with any evidence of bridging bone in the interbody space (either around or through

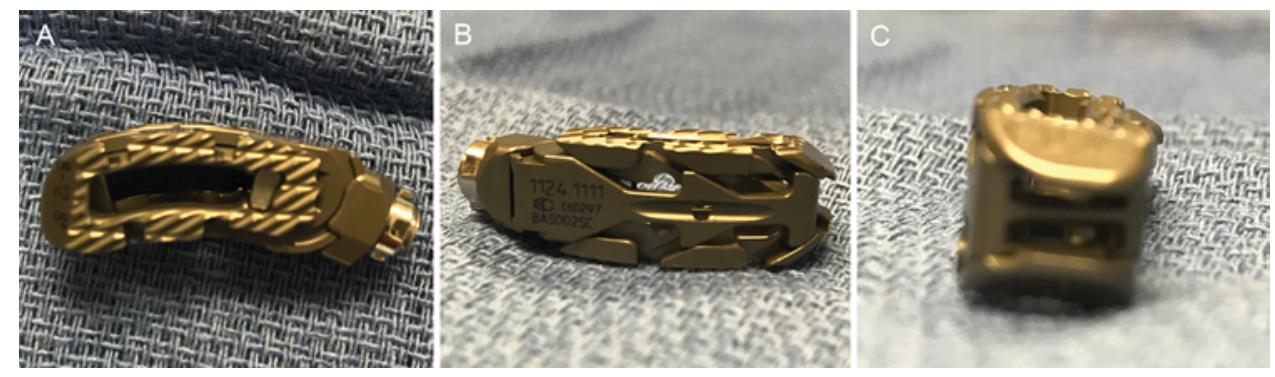

FIG. 1. Photographs of the Altera cage-this is a $31-\mathrm{mm}$ length $\times 10-\mathrm{mm}$ width, $15^{\circ}$ lordotic cage expanded to $13 \mathrm{~mm}$. A: Topdown view illustrates graft window and cage footprint. B: Front view of the cage shows the expansion mechanism. C: Lateral view illustrates the lordotic angle built into the cage. 

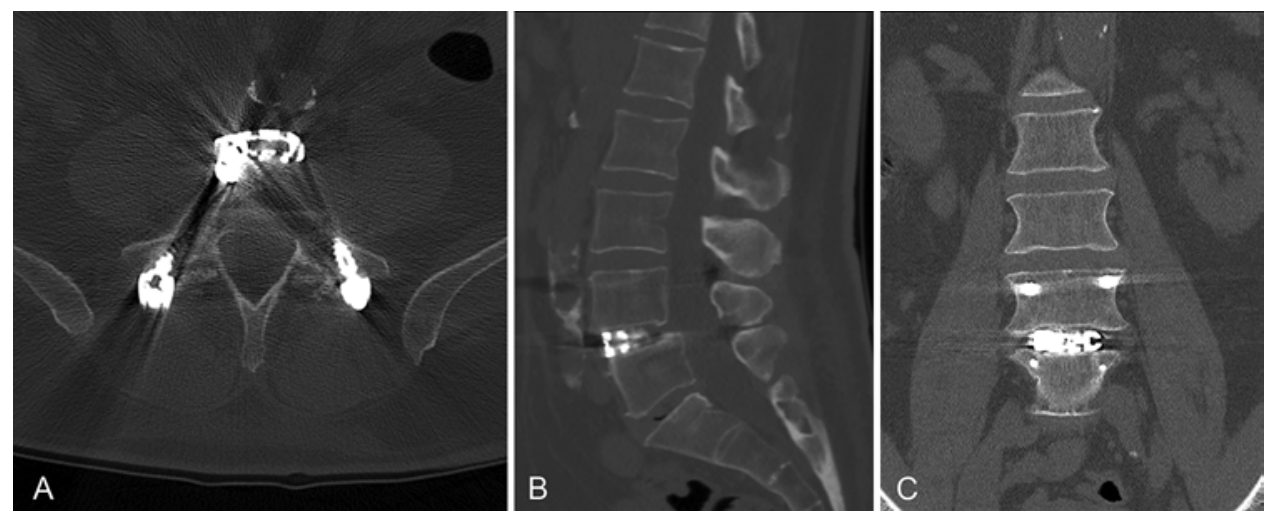

FIG. 2. Postoperative CT views obtained at 1 year postsurgery. A: Axial CT image showing $31 \times 10-\mathrm{mm}$ cage in appropriate position. B: Sagittal view, CT image. C: Coronal view, CT image.

the cage), and/or bridging of the facets being considered a bony fusion. Subsidence was measured using both CT scans and radiographs.

\section{Description of Surgical Technique}

All operations were performed by the senior author (V.C.). The patient is placed prone by using a Jackson frame (Mizuho) with a horizontal chest pad as well as hip and thigh pads. Two $25-\mathrm{mm}$ paramedian incisions are made $4 \mathrm{~cm}$ (or wider, depending on patient's body habitus) off the midline. Using fluoroscopy guidance, a Jamshidi needle is used to cannulate the pedicle, and a $\mathrm{K}$-wire is left in place. Depending on the laterality of the symptoms, the approach for the TLIF is made from one side, and an incision is made in the lumbosacral fascia. A Cobb elevator is used to dissect the muscle attachments off the facet complex. Sequential tissue dilators are docked onto the facet with a medial trajectory, and an expandable retractor with blades of appropriate depth is inserted over the dilator and secured to a rigid arm (MARS 3VL, Globus Medical).

The rest of the TLIF is performed using an intraoperative microscope. Using a high-speed burr, a total facetectomy and a hemilaminectomy is performed to expose the dura mater and traversing nerve root. The disc is incised sharply, and disc material is removed using a combination of pituitary rongeur, disc shavers, and curettes (Fig. 3A). Graft materials are inserted into the disc space, and then the interbody cage is packed with grafting material and hammered into the disc space. Using fluoroscopy, the cage is inserted until its tip reaches the anterior anulus (Fig. 3B). The articulation mechanism is then released, and the cage is rotated into as lateral an orientation as possible (Fig. 3C). The cage is then expanded up to the appropriate height, which is torque limited, and confirmed on intraoperative fluoroscopy (Fig. 3D). Additional graft material is then further filled into the expanded interbody spacer with the aid of a special funnel. More graft is then packed behind the spacer until level with the posterior wall of the vertebral body. The microscope and retractor are then removed. On the contralateral side, a small stab incision in the lumbosacral fascia is performed, and soft-tissue dilators are then passed around the K-wires bilaterally. Pedicle screws are then placed over the K-wire bilaterally. On the TLIF side a rod is placed down the extended screw tabs through the preexisting fascial incision. On the contralateral side, our preference is to pass the rod under the fascia through the extended screw tabs without cutting the fascia between the screws. Locking screws are then placed, and the extended tabs are broken off the screw heads (Fig. 3E).

\section{Statistical Analysis}

Descriptive statistics of means, SDs, frequencies, and percentages were computed for the demographic and surgical information. Wilcoxon 2-sample tests were done to

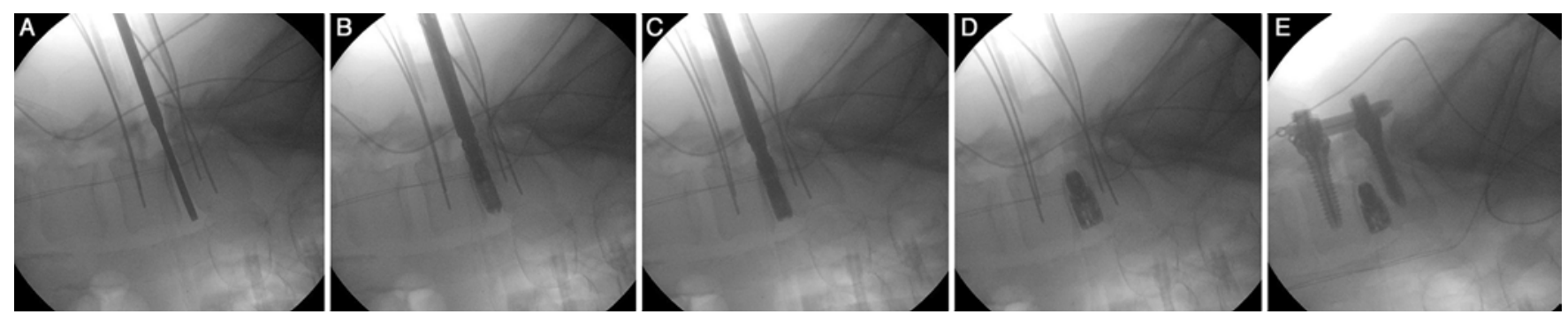

FIG. 3. Sequence of steps needed to place the cage. A: Preparation of the disc space. B: Insertion of the collapsed cage from a traditional TLIF trajectory. C: Articulation of the hinge allowing for horizontal placement across the anterior longitudinal ligament. D: Expansion of the cage in a lordotic fashion. E: Placement of the cage, and of posterolateral pedicle screws. 
TABLE 1. Demographic and surgical information in 44 patients with spondylolisthesis

\begin{tabular}{|c|c|}
\hline Variable & All Pts \\
\hline \multicolumn{2}{|l|}{ Age in yrs } \\
\hline Mean \pm SD & $63.1 \pm 12.6$ \\
\hline Median (range) & $66.5(26-85)$ \\
\hline \multicolumn{2}{|l|}{ Sex } \\
\hline Female & $28(64 \%)$ \\
\hline Male & $16(36 \%)$ \\
\hline \multicolumn{2}{|l|}{ Race } \\
\hline African American & $4(9 \%)$ \\
\hline Caucasian & $39(89 \%)$ \\
\hline Hispanic & $1(2 \%)$ \\
\hline \multicolumn{2}{|l|}{ Levels } \\
\hline 1 & $39(89 \%)$ \\
\hline 2 & $5(11 \%)$ \\
\hline \multicolumn{2}{|l|}{ BMI } \\
\hline Mean \pm SD & $30.5 \pm 6.4$ \\
\hline Median (range) & $29.8(20.67-45.1)$ \\
\hline \multicolumn{2}{|l|}{ BMI group } \\
\hline$<25$ & $13(30 \%)$ \\
\hline 25 to $<30$ & $9(20 \%)$ \\
\hline$\geq 30$ & $22(50 \%)$ \\
\hline \multicolumn{2}{|l|}{$\mathrm{EBL}$ in $\mathrm{ml}$} \\
\hline \multicolumn{2}{|l|}{ All pts } \\
\hline Mean \pm SD & $64.8 \pm 43.5$ \\
\hline Median (range) & $50(25-200)$ \\
\hline \multicolumn{2}{|l|}{1 level $^{*}$} \\
\hline Mean \pm SD & $58.3 \pm 37.2$ \\
\hline Median (range) & $50(25-100)$ \\
\hline \multicolumn{2}{|l|}{2 levels } \\
\hline Mean \pm SD & $115 \pm 60.2$ \\
\hline Median (range) & $100(50-200)$ \\
\hline \multicolumn{2}{|l|}{ ASA score } \\
\hline II & $18(41 \%)$ \\
\hline III & $23(52 \%)$ \\
\hline IV & $3(7 \%)$ \\
\hline \multicolumn{2}{|l|}{ OR time in min } \\
\hline \multicolumn{2}{|l|}{ All pts } \\
\hline Mean \pm SD & $166.5 \pm 55.6$ \\
\hline Median (range) & $140(100-364)$ \\
\hline \multicolumn{2}{|l|}{1 level† } \\
\hline Mean \pm SD & $156.9 \pm 51$ \\
\hline Median (range) & $139(100-364)$ \\
\hline \multicolumn{2}{|l|}{2 levels } \\
\hline Mean \pm SD & $241 \pm 27.3$ \\
\hline Median (range) & $250(201-266)$ \\
\hline
\end{tabular}

$\mathrm{ASA}=$ American Society of Anesthesiologists; $\mathrm{BMI}=$ body mass index; $\mathrm{pts}=$ patients.

Values are expressed as the mean \pm SD, median (range), or number (\%), as indicated.

${ }^{*} p=0.027$ comparing 1 - to 2-level operations.

$\dagger p=0.003$ comparing 1 - to 2 -level operations. compare groups of patients for EBL and OR time. For the radiographic measures, means and SEs were computed using methods that take into account the correlation within a patient with a 2-level procedure. Paired t-tests were used to compare pre- and postoperative measures for lordosis, PI-LL mismatch, SVA, and change in listhesis (in singlelevel patients only), as well as changes from baseline to 90 days and 1 year for PROs. For pre- to postoperative changes in segmental angles and segmental height, methods similar to paired t-tests that take into account multilevel procedures were done. Spearman correlation coefficients were computed to assess the relationships (associations) between pre- and postoperative changes in radiographic measures and changes in PROs. For the patients with 2-level procedures, the maximum pre- to postoperative change over the 2 levels was used in this correlation analysis. All testing was done at the 0.05 testing level. We used SAS version 9.4 to perform all statistical analyses.

\section{Results \\ General Findings}

There were 44 patients included in this study, with 39 (89\%) having a single-level procedure and 5 having 2-level procedures. The mean age for all patients was 63.1 years (range 26-85 years), 64\% were female, and $89 \%$ were Caucasian. All of the 39 single-level interventions were performed for spondylolisthesis. In the 5 patients treated with multilevel operations, 2 of the 10 total levels had spondylolisthesis. Three (7\%) cases were isthmic, whereas the remainder were degenerative. The median OR time for the single-level procedures was 139 minutes, and for the 2-level procedures it was 250 minutes $(p=0.003)$. For the single-level procedures there appeared to be a learning curve, with the first 10 procedures having a median OR time of 182 minutes and the remaining procedures having a median OR time of 135 minutes $(\mathrm{p}<0.001)$. The mean EBL was $58.3 \mathrm{ml}$ for the single-level procedures and 115 $\mathrm{ml}$ for the 2-level procedures $(\mathrm{p}=0.027)$. Among the single-level procedures, there was a trend toward decreased blood loss over time; for the first 10 procedures the mean EBL was $75.5 \mathrm{ml}(\mathrm{SD} 32.5 \mathrm{ml})$ and for the remaining procedures the mean EBL was $52.3 \mathrm{ml}(\mathrm{SD} 37.3 \mathrm{ml} ; \mathrm{p}=$ $0.057)$. More demographic and surgical information can be found in Table 1. Of the 44 patients, 16 (36\%) had been followed for at least 2 years, $22(50 \%)$ for at least 1 year, and $6(14 \%)$ for almost 1 year at the time of this report. The median follow-up for all patients was 1.5 years.

\section{Radiographic and Clinical Outcome Measures}

Significant improvement in the degree of spondylolisthesis and segmental height and angle were noted. On average, spondylolisthesis was corrected by $4.3 \mathrm{~mm}$ (preoperative $6.69 \mathrm{~mm}$, postoperative $2.39 \mathrm{~mm}, \mathrm{p}<0.001)$, segmental angle was improved by $4.94^{\circ}$ (preoperative $5.63^{\circ}$, postoperative $10.58^{\circ}, \mathrm{p}<0.001$ ), and segmental height increased by $3.1 \mathrm{~mm}$ (preoperative $5.09 \mathrm{~mm}$, postoperative $8.19 \mathrm{~mm}, \mathrm{p}<0.001)$. The differences between pre- and postoperative measurements of lordosis, PI-LL mismatch, SVA, and PT were not significant (Table 2).

Of the 44 patients, 24 (54\%) had PROs measured at 
TABLE 2. Preoperative and postoperative radiographic measures in 44 patients with spondylolisthesis

\begin{tabular}{|c|c|c|c|c|}
\hline Radiographic Measures & No. of Pts & Mean & SE & p Value* \\
\hline \multicolumn{5}{|l|}{$\begin{array}{l}\text { Spondylolisthesis in mm } \\
\text { (1-level ops only) }\end{array}$} \\
\hline Preop & 39 & 6.69 & 0.63 & \\
\hline Postop & 39 & 2.39 & 0.40 & \\
\hline Postop - preop & 39 & -4.30 & 0.62 & $<0.001$ \\
\hline \multicolumn{5}{|l|}{ LL } \\
\hline Preop & 35 & 47.37 & 2.32 & \\
\hline Postop & 40 & 50.55 & 1.95 & \\
\hline Postop - preop & 33 & 2.48 & 1.49 & 0.104 \\
\hline \multicolumn{5}{|l|}{ PI-LL mismatch } \\
\hline Preop & 38 & 0.50 & 2.54 & \\
\hline Postop & 38 & -2.45 & 3.58 & \\
\hline Postop - preop & 36 & -1.28 & 2.27 & 0.576 \\
\hline \multicolumn{5}{|l|}{ Segmental angle } \\
\hline Preop & 49 & 5.63 & 0.70 & \\
\hline Postop & 49 & 10.58 & 0.54 & \\
\hline Postop - preop & 49 & 4.94 & 0.76 & $<0.001$ \\
\hline \multicolumn{5}{|l|}{ Segmental height } \\
\hline Preop & 49 & 5.09 & 0.28 & \\
\hline Postop & 49 & 8.19 & 0.31 & \\
\hline Postop - preop & 49 & 3.10 & 0.29 & $<0.001$ \\
\hline \multicolumn{5}{|l|}{ SVA } \\
\hline Preop & 33 & 3.64 & 0.62 & \\
\hline Postop & 38 & 3.51 & 0.65 & \\
\hline Postop - preop & 28 & -0.48 & 0.45 & 0.299 \\
\hline \multicolumn{5}{|l|}{ PT } \\
\hline Preop & 35 & 16.23 & 1.78 & \\
\hline Postop & 37 & 15.54 & 1.34 & \\
\hline Postop - preop & 29 & -0.10 & 1.33 & 0.938 \\
\hline
\end{tabular}

Variations in number of patients reflect some inconsistency of compliance in collecting PRO data.

* $p$ values were calculated from paired t-tests by using methods for comparing pre- to postoperative measurements.

baseline and 90 days. Of the 38 patients with at least 1 year since surgery, $23(61 \%)$ of them had PROs measured at baseline and 1 year. For all 3 PROs (i.e., ODI, back pain, leg pain), there was a significant improvement observed when we compared baseline to 90-day outcomes ( $\mathrm{p}<$ $0.001)$. The ODI decreased by 15.3 points $(\mathrm{p}<0.001)$ at 90 days compared with baseline and was decreased by 15.7 points $(\mathrm{p}=0.001)$ at 1 year compared with baseline. Back pain and leg pain also declined significantly, and this improvement was sustained at 1 year. The ODI and back and leg pain scores were still lower at 2 years, but these findings were not statistically significant given the small number of patients with baseline and 2-year PROs (Table 3).

\section{Associations of Changes in Radiographic Measures and Changes in PRO}

The relationship between the postoperative SVA and
TABLE 3. Patient-reported outcomes in individuals with spondylolisthesis

\begin{tabular}{|c|c|c|c|c|}
\hline PRO & Follow-Up Time & $\begin{array}{l}\text { No. of } \\
\text { Pts }\end{array}$ & Mean \pm SD & $\begin{array}{c}p \\
\text { Value* }^{*}\end{array}$ \\
\hline \multirow[t]{7}{*}{ ODI } & Baseline & 29 & $39.2 \pm 13.2$ & \\
\hline & 90 days & 30 & $27.5 \pm 20.7$ & \\
\hline & $\begin{array}{l}\text { Change from baseline to } \\
90 \text { days }\end{array}$ & 24 & $15.3 \pm 18.4$ & $<0.001$ \\
\hline & $1 \mathrm{yr}$ & 34 & $27.4 \pm 19.0$ & \\
\hline & $\begin{array}{l}\text { Change from baseline } \\
\text { to } 1 \mathrm{yr}\end{array}$ & 23 & $15.7 \pm 20.1$ & 0.001 \\
\hline & $2 \mathrm{yrs}$ & 11 & $32.5 \pm 20.4$ & \\
\hline & $\begin{array}{l}\text { Change from baseline to } \\
2 \mathrm{yrs}\end{array}$ & 6 & $9.8 \pm 15.7$ & 0.186 \\
\hline \multirow[t]{7}{*}{ Back pain } & Baseline & 27 & $6.7 \pm 2.4$ & \\
\hline & 90 days & 31 & $3.3 \pm 3.0$ & \\
\hline & $\begin{array}{l}\text { Change from baseline to } \\
90 \text { days }\end{array}$ & 24 & $3.7 \pm 3.3$ & $<0.001$ \\
\hline & $1 \mathrm{yr}$ & 32 & $4.5 \pm 3.9$ & \\
\hline & $\begin{array}{l}\text { Change from baseline } \\
\text { to } 1 \mathrm{yr}\end{array}$ & 20 & $3.3 \pm 4.6$ & 0.004 \\
\hline & $2 \mathrm{yrs}$ & 12 & $5.1 \pm 4.2$ & \\
\hline & $\begin{array}{l}\text { Change from baseline to } \\
2 \text { yrs }\end{array}$ & 6 & $3.2 \pm 4.2$ & 0.125 \\
\hline \multirow[t]{7}{*}{ Leg pain } & Baseline & 27 & $6.9 \pm 2.6$ & \\
\hline & 90 days & 31 & $3.7 \pm 3.8$ & \\
\hline & $\begin{array}{l}\text { Change from baseline to } \\
90 \text { days }\end{array}$ & 24 & $3.7 \pm 3.4$ & $<0.001$ \\
\hline & $1 \mathrm{yr}$ & 32 & $4.3 \pm 3.2$ & \\
\hline & $\begin{array}{l}\text { Change from baseline } \\
\text { to } 1 \mathrm{yr}\end{array}$ & 20 & $3.8 \pm 3.3$ & $<0.001$ \\
\hline & $2 \mathrm{yrs}$ & 11 & $4.4 \pm 3.6$ & \\
\hline & $\begin{array}{l}\text { Change from baseline to } \\
2 \text { yrs }\end{array}$ & 6 & $4.0 \pm 4.1$ & 0.064 \\
\hline
\end{tabular}

Variations in number of patients reflect some inconsistency of compliance in collecting PRO data.

* $p$ values were calculated from paired t-tests.

change in back pain was significant $(\mathrm{r}=-0.558, \mathrm{p}=$ 0.013 ), with a smaller postoperative SVA associated with larger changes in back pain at 90 days. In addition, a larger decrease in spondylolisthesis was associated with larger changes (improvements) in ODI and back pain scores $(r=-0.425, p=0.043$, and $r=-0.43, p=0.031$, respectively). Also, a larger decrease in PT was associated with a larger change (improvement) in back pain scores $(r=-0.548, p=0.043)$. None of the other correlation coefficients were significant for the 90-day outcomes. For the 1-year PROs, the relationship between the change in PT and the changes in ODI and NRS back pain were significant $(\mathrm{r}=0.612, \mathrm{p}=0.009$, and $\mathrm{r}=-0.803, \mathrm{p}=0.001$, respectively) with larger decreases in $\mathrm{PT}$ associated with larger improvements in ODI and back pain. None of the other correlation coefficients were significant for the 1 -year outcomes. 
TABLE 4. Radiographic outcomes by time point in 44 patients with spondylolisthesis

\begin{tabular}{|c|c|c|c|c|c|}
\hline Outcome & Preop & 3 Mos & 6 Mos & $1 Y r$ & 2 Yrs \\
\hline \multicolumn{6}{|l|}{ Sagittal balance } \\
\hline $\mathrm{PI}$ & $50^{\circ}(n=35)$ & & & & \\
\hline LL & $47.37^{\circ}(n=35)$ & $49.00^{\circ}(n=33)$ & $52.71^{\circ}(n=32)$ & $50.55^{\circ} ; p=0.104(n=40)$ & $51.6^{\circ} ; p=0.136(n=15)$ \\
\hline PT & $16.23^{\circ}(n=35)$ & $15.61^{\circ}(n=33)$ & $15.0^{\circ}(n=32)$ & $15.54^{\circ} ; p=0.938(n=37)$ & $14.6^{\circ} ; p=0.297(n=15)$ \\
\hline SVA & $3.64 \mathrm{~cm}(\mathrm{n}=33)$ & $3.89 \mathrm{~cm}(\mathrm{n}=33)$ & $3.49 \mathrm{~cm}(\mathrm{n}=32)$ & $3.51 \mathrm{~cm} ; p=0.299(n=38)$ & $3.06 \mathrm{~cm} ; p=0.64(n=15)$ \\
\hline Segmental height & $5.09 \mathrm{~mm}(\mathrm{n}=49)$ & $8.06 \mathrm{~mm}(\mathrm{n}=33)$ & $8.16 \mathrm{~mm}(\mathrm{n}=32)$ & $8.19 \mathrm{~mm} ; p<0.001(n=49)$ & $8.30 \mathrm{~mm} ; p<0.001(n=19)$ \\
\hline Segmental angle & $5.63^{\circ}(n=49)$ & $9.33^{\circ}(n=33)$ & $9.23^{\circ}(n=32)$ & $10.58^{\circ} ; p<0.0001(n=49)$ & $8.75^{\circ} ; p=0.015(n=19)$ \\
\hline Fusion & NA & NA & $26 / 48$ levels (54\%) & $46 / 48$ levels $(96 \%)$ & 7/7 w/ 2-yr CT (100\%) \\
\hline
\end{tabular}

$\mathrm{NA}=$ not applicable.

Variations in number of patients reflect some inconsistency of compliance in collecting PRO data.

\section{Fusion, Endplate Violation, and Subsidence}

There were 48 operative levels in 43 patients with 6-month fusion information available. At 6 months, 26 levels (54\%) had a fusion. Of the 22 levels without fusion at 6 months, 20 had fusion at 1 year, 1 had not completely fused, and 1 had not yet been followed for 1 year. Overall for this study there was a $96 \%$ fusion rate (Table 4).

Fourteen patients were noted to have endplate violation on intraoperative fluoroscopy during placement of the cage. Only 3 of these had progression of their subsidence, with an overall subsidence rate of $6 \%$ (3 of 49) visible on postoperative $\mathrm{CT}$, and none of these patients have required any additional intervention. Our standard protocol is to assess these patients up to 2 years, and if there is evidence of additional subsidence, these patients are set to be followed annually with serial films.

\section{Discussion}

This study illustrates generally favorable radiographic results on short-term follow-up review after a crescentshaped articulating expandable cage had been inserted for 1- and 2-level MIS TLIF procedures for patients with spondylolisthesis (Fig. 4). The use of this lordotic, expandable cage achieved its 3 primary radiographic objectives: reduction in the degree of spondylolisthesis, restoration of
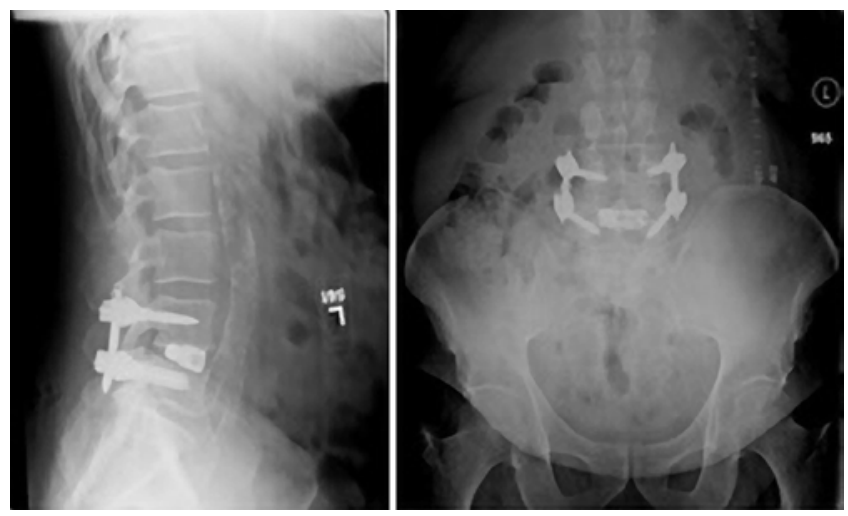

FIG. 4. Postoperative radiographic views of the fusion construct. intradiscal height without significant subsidence, and improvement in the segmental lordosis.

\section{Key Results}

The use of this lordotic cage illustrates the potential for significant segmental correction within the sagittal plane, with a mean improvement of $4.94^{\circ}$ of lordosis at a mean follow-up of 1.5 years. By way of historical comparison with traditional MIS TLIF, other studies have demonstrated $2^{\circ}-3^{\circ}$ of segmental correction in the sagittal plane. $\cdot^{15,21,23,48}$ In comparison with other forms of sagittal correction, historically MIS TLIF has shown only modest improvements in segmental lordotic angle. Additionally, the increase in segmental lordotic restoration in this study compares favorably to a weighted average increase of $3.9^{\circ}$ published in a review by Uribe et al. ${ }^{43}$ Despite these positive findings, it is important to note that the question whether improvement in LL translates into actual improved clinical outcomes for treatment of spondylolisthesis has not been reliably answered in the literature. ${ }^{31}$ The same can also be said for height restoration, which was also improved in this study, but is unproven regarding clinical efficacy.

For sagittal alignment parameters, given that the vast majority of patients only had 1-level pathology, we did not expect to observe a tremendous degree of sagittal imbalance preoperatively. Therefore, we did not expect to dramatically alter the overall sagittal balance postoperatively. Our study does demonstrate short-term improvements in back pain correlated with improving SVA at 90 days, as well as an association with decreasing PT and improvements in ODI and back pain at 1 year, consistent with what has been previously reported..$^{5,18,25,34,41}$ Although sagittal parameters are more commonly associated with preoperative planning and outcomes in deformity surgery, our results do show that even in 1- and 2-level lumbar fusion surgery, maintenance of sagittal balance parameters can correlate with better clinical outcome.

With regard to the reduction of spondylolisthesis and its effect on clinical outcome, our study did identify a statistically significant correlation between the two, with greater reduction of spondylolisthesis associated with larger improvements in ODI and back pain scores. Although this finding is encouraging, a recent systematic review did not find sufficient support for this in the literature. ${ }^{31}$ One of the 
chief limitations noted in this review is the lack of adequate well-powered studies, warranting further investigation. Overall, our results are consistent with other studies that demonstrate clinical improvements in disability, back pain, and leg pain after MIS TLIF. Bin Abd Razak et al. demonstrated similar reductions in ODI, and NRS back and leg pain, which were durable over 5 years. ${ }^{1}$ Similar to Fan et al., who studied MIS TLIF with or without the use of reduction, no significant improvement in ODI or NRS back or leg pain was associated with the degree of reduction in spondylolisthesis in our patients. ${ }^{8}$ In this study, improvements in back disability on average surpassed the published minimum clinically important difference for $\mathrm{ODI}^{27}$ and demonstrated a durable reduction throughout the duration of follow-up.

Another consideration with regard to this particular implant is that historically there has been some suspicion about expandable interbody cages regarding subsidence and risk for pseudarthrodesis. In addition, the cage material is of concern, given the relatively high modulus of elasticity of titanium relative to bone as compared with polyetheretherketone, which has become more widely used. Overall, our rate of fusion as verified by CT compares favorably with series in which nonexpandable cages were used, and notably none of the patients in this series have required a return to surgery for pseudarthrosis. Three of our patients demonstrated radiographic subsidence, with none of the cases being clinically significant (i.e., requiring a reoperation or resulting in recurrent symptoms). Although further long-term follow-up is necessary (5-10 years ideally), it appears that the fact that the cage is titanium does not seem to impart a significant risk of subsidence.

\section{Generalizability of Findings}

Our results are generalizable to MIS TLIF surgery, and revolve primarily around the use of a specific cage design. There is a recent study by Hawasli et al., which showed comparable results using the same implant. ${ }^{14}$ Currently, to our knowledge, there are no other cages available in the US with a similar design. Although some may advocate that fusion (and TLIF in particular, given its additional operative risks compared with laminectomy alone-which include longer OR time, greater blood loss, risks of pseudarthrosis, risks pertaining to hardware, increased length of stay, and so on) may not be indicated for the treatment of degenerative spondylolisthesis, the question whether MIS TLIF is necessary for the management of degenerative spondylolisthesis is beyond the scope of this paper. Our goal was to present clinical and radiographic outcomes for an MIS TLIF cohort for the treatment of degenerative spondylolisthesis in which this particular interbody cage is used.

\section{Limitations of the Study}

There are some notable limitations of our study. Our study represents a single surgeon's experience with a relatively small sample size. In addition, our mean follow-up of 1.5 years is relatively short, and further long-term followup is warranted to demonstrate whether our radiographic findings remain durable. Future study will evaluate whether increased segmental correction has a protective effect on the development of adjacent-segment degeneration and the need for additional interventions. Finally, there are some inconsistencies with the collection of PRO data at different time points; most notably there were a fair number of patients who had missing baseline data, which should be noted when interpreting our clinical results.

\section{Conclusions}

This study demonstrates that favorable outcomes can be obtained with the use of a titanium, crescent-shaped, articulating, expandable cage in MIS TLIF for 1- and 2-level spondylolisthesis. The use of such technology does demonstrate the potential for additional segmental lordotic restoration as compared with historically published data. It remains to be seen whether these radiographic differences will translate into improved clinical outcomes in the longer term.

\section{Acknowledgments}

This study was done within the framework of the Michigan Spine Surgery Improvement Collaborative (MSSIC), which is funded by Blue Cross Blue Shield of Michigan. Much of the PRO data was collected using MSSIC abstractors, and this would not have been possible without their support.

\section{References}

1. Bin Abd Razak HR, Dhoke P, Tay KS, Yeo W, Yue WM: Single-level minimally invasive transforaminal lumbar interbody fusion provides sustained improvements in clinical and radiological outcomes up to 5 years postoperatively in patients with neurogenic symptoms secondary to spondylolisthesis. Asian Spine J 11:204-212, 2017

2. Brodano GB, Martikos K, Lolli F, Gasbarrini A, Cioni A, Bandiera S, et al: Transforaminal lumbar interbody fusion in degenerative disk disease and spondylolisthesis grade I: minimally invasive versus open surgery. J Spinal Disord Tech 28:E559-E564, 2015

3. Cheng X, Zhang K, Sun X, Zhao C, Li H, Ni B, et al: Clinical and radiographic outcomes of bilateral decompression via a unilateral approach with transforaminal lumbar interbody fusion for degenerative lumbar spondylolisthesis with stenosis. Spine J 17:1127-1133, 2017

4. de Kunder SL, van Kuijk SMJ, Rijkers K, Caelers IJMH, van Hemert WLW, de Bie RA, et al: Transforaminal lumbar interbody fusion (TLIF) versus posterior lumbar interbody fusion (PLIF) in lumbar spondylolisthesis: a systematic review and meta-analysis. Spine J [epub ahead of print], 2017

5. Djurasovic MO, Carreon LY, Glassman SD, Dimar JR II, Puno RM, Johnson JR: Sagittal alignment as a risk factor for adjacent level degeneration: a case-control study. Orthopedics 31:546, 2008

6. Epstein NE: More nerve root injuries occur with minimally invasive lumbar surgery: Let's tell someone. Surg Neurol Int 7 (Suppl 3):S96-S101, 2016

7. Fan G, Gu G, Zhu Y, Guan X, Hu A, Wu X, et al: Minimally invasive transforaminal lumbar interbody fusion for isthmic spondylolisthesis: in situ versus reduction. World Neurosurg 90:580-587 e581, 2016

8. Fan G, Zhang H, Guan X, Gu G, Wu X, Hu A, et al: Patientreported and radiographic outcomes of minimally invasive transforaminal lumbar interbody fusion for degenerative spondylolisthesis with or without reduction: A comparative study. J Clin Neurosci 33:111-118, 2016

9. Ghasemi AA: Transforaminal lumbar interbody fusion versus instrumented posterolateral fusion in degenerative spondylolisthesis: an attempt to evaluate the superiority of 
one method over the other. Clin Neurol Neurosurg 150:1-5, 2016

10. Ghogawala Z, Barker FG II, Benzel EC: Fusion surgery for lumbar spinal stenosis. N Engl J Med 375:600-601, 2016

11. Ghogawala Z, Dziura J, Butler WE, Dai F, Terrin N, Magge $\mathrm{SN}$, et al: Laminectomy plus fusion versus laminectomy alone for lumbar spondylolisthesis. N Engl J Med 374:14241434, 2016

12. Glassman SD, Bridwell K, Dimar JR, Horton W, Berven S, Schwab F: The impact of positive sagittal balance in adult spinal deformity. Spine (Phila Pa 1976) 30:2024-2029, 2005

13. Glassman SD, Carreon LY, Ghogawala Z, Foley KT, McGirt MJ, Asher AL: Benefit of transforaminal lumbar interbody fusion vs posterolateral spinal fusion in lumbar spine disorders: a propensity-matched analysis from the National Neurosurgical Quality and Outcomes Database Registry. Neurosurgery 79:397-405, 2016

14. Hawasli AH, Khalifeh JM, Chatrath A, Yarbrough CK, Ray WZ: Minimally invasive transforaminal lumbar interbody fusion with expandable versus static interbody devices: radiographic assessment of sagittal segmental and pelvic parameters. Neurosurg Focus 43(2):E10, 2017

15. Kim JS, Kang BU, Lee SH, Jung B, Choi YG, Jeon SH, et al: Mini-transforaminal lumbar interbody fusion versus anterior lumbar interbody fusion augmented by percutaneous pedicle screw fixation: a comparison of surgical outcomes in adult low-grade isthmic spondylolisthesis. J Spinal Disord Tech 22:114-121, 2009

16. Kim JY, Park JY, Kim KH, Kuh SU, Chin DK, Kim KS, et al: Minimally invasive transforaminal lumbar interbody fusion for spondylolisthesis: comparison between isthmic and degenerative spondylolisthesis. World Neurosurg 84:12841293, 2015

17. Kim YJ, Bridwell KH, Lenke LG, Rhim S, Cheh G: An analysis of sagittal spinal alignment following long adult lumbar instrumentation and fusion to L5 or S1: can we predict ideal lumbar lordosis? Spine (Phila Pa 1976) 31:2343-2352, 2006

18. Kumar MN, Baklanov A, Chopin D: Correlation between sagittal plane changes and adjacent segment degeneration following lumbar spine fusion. Eur Spine J 10:314-319, 2001

19. Lafage R, Ferrero E, Henry JK, Challier V, Diebo B, Liabaud $\mathrm{B}$, et al: Validation of a new computer-assisted tool to measure spino-pelvic parameters. Spine J 15:2493-2502, 2015

20. Lau D, Khan A, Terman SW, Yee T, La Marca F, Park P: Comparison of perioperative outcomes following open versus minimally invasive transforaminal lumbar interbody fusion in obese patients. Neurosurg Focus 35(2):E10, 2013

21. Lee DY, Jung TG, Lee SH: Single-level instrumented miniopen transforaminal lumbar interbody fusion in elderly patients. J Neurosurg Spine 9:137-144, 2008

22. Lee N, Kim KN, Yi S, Ha Y, Shin DA, Yoon DH, et al: Comparison of outcomes of anterior, posterior, and transforaminal lumbar interbody fusion surgery at a single lumbar level with degenerative spinal disease. World Neurosurg 101:216-226, 2017

23. Min SH, Yoo JS: The clinical and radiological outcomes of multilevel minimally invasive transforaminal lumbar interbody fusion. Eur Spine J 22:1164-1172, 2013

24. Mummaneni PV, Bisson EF, Kerezoudis P, Glassman S, Foley K, Slotkin JR, et al: Minimally invasive versus open fusion for Grade I degenerative lumbar spondylolisthesis: analysis of the Quality Outcomes Database. Neurosurg Focus 43(2):E11, 2017

25. Nakai S, Yoshizawa H, Kobayashi S: Long-term follow-up study of posterior lumbar interbody fusion. J Spinal Disord 12:293-299, 1999

26. Nandyala SV, Fineberg SJ, Pelton M, Singh K: Minimally invasive transforaminal lumbar interbody fusion: one surgeon's learning curve. Spine J 14:1460-1465, 2014

27. Nixon AT, Smith ZA, Lawton CD, Wong AP, Dahdaleh NS, Koht A, et al: Bilateral neurological deficits following unilateral minimally invasive TLIF: a review of four patients. Surg Neurol Int 5 (Suppl 7):S317-S324, 2014

28. Park Y, Ha JW, Lee YT, Sung NY: Minimally invasive transforaminal lumbar interbody fusion for spondylolisthesis and degenerative spondylosis: 5-year results. Clin Orthop Relat Res 472:1813-1823, 2014

29. Parker SL, Mendenhall SK, Shau DN, Zuckerman SL, Godil SS, Cheng JS, et al: Minimally invasive versus open transforaminal lumbar interbody fusion for degenerative spondylolisthesis: comparative effectiveness and cost-utility analysis. World Neurosurg 82:230-238, 2014

30. Rajakumar DV, Hari A, Krishna M, Sharma A, Reddy M: Complete anatomic reduction and monosegmental fusion for lumbar spondylolisthesis of Grade II and higher: use of the minimally invasive "rocking" technique. Neurosurg Focus 43(2):E12, 2017

31. Rhee C, Visintini S, Dunning CE, Oxner WM, Glennie RA: Does restoration of focal lumbar lordosis for single level degenerative spondylolisthesis result in better patientreported clinical outcomes? A systematic literature review. J Clin Neurosci 44:95-100, 2017

32. Saetia K, Phankhongsab A, Kuansongtham V, Paiboonsirijit $\mathrm{S}$ : Comparison between minimally invasive and open transforaminal lumbar interbody fusion. J Med Assoc Thai 96:41-46, 2013

33. Scheer JK, Auffinger B, Wong RH, Lam SK, Lawton CD, Nixon AT, et al: Minimally invasive transforaminal lumbar interbody fusion (TLIF) for spondylolisthesis in 282 patients: in situ arthrodesis versus reduction. World Neurosurg 84:108-113, 2015

34. Schwab FJ, Blondel B, Bess S, Hostin R, Shaffrey CI, Smith JS, et al: Radiographical spinopelvic parameters and disability in the setting of adult spinal deformity: a prospective multicenter analysis. Spine (Phila Pa 1976) 38:E803-E812, 2013

35. Sclafani JA, Raiszadeh K, Raiszadeh R, Kim P, Doerr T, Siddiqi F, et al: Validation and analysis of a multi-site MIS prospective registry through sub-analysis of an MIS TLIF Subgroup. Int J Spine Surg 8:8, 2014

36. Senteler M, Weisse B, Snedeker JG, Rothenfluh DA: Pelvic incidence-lumbar lordosis mismatch results in increased segmental joint loads in the unfused and fused lumbar spine. Eur Spine J 23:1384-1393, 2014

37. Serban D, Calina N, Tender G: Standard versus minimally invasive transforaminal lumbar interbody fusion: a prospective randomized study. BioMed Res Int 2017:7236970, 2017

38. Singh K, Nandyala SV, Marquez-Lara A, Fineberg SJ, Oglesby M, Pelton MA, et al: A perioperative cost analysis comparing single-level minimally invasive and open transforaminal lumbar interbody fusion. Spine J 14:1694-1701, 2014

39. Sulaiman WA, Singh M: Minimally invasive versus open transforaminal lumbar interbody fusion for degenerative spondylolisthesis grades 1-2: patient-reported clinical outcomes and cost-utility analysis. Ochsner J 14:32-37, 2014

40. Tay KS, Bassi A, Yeo W, Yue WM: Intraoperative reduction does not result in better outcomes in low-grade lumbar spondylolisthesis with neurogenic symptoms after minimally invasive transforaminal lumbar interbody fusion-a 5-year follow-up study. Spine J 16:182-190, 2016

41. Tempel ZJ, Gandhoke GS, Bolinger BD, Khattar NK, Parry PV, Chang YF, et al: The influence of pelvic incidence and lumbar lordosis mismatch on development of symptomatic adjacent level disease following single-level transforaminal lumbar interbody fusion. Neurosurgery 80:880-886, 2017 
42. Tye EY, Tanenbaum JE, Alonso AS, Xiao R, Steinmetz MP, Mroz TE, et al: Circumferential fusion: a comparative analysis between anterior lumbar interbody fusion with posterior pedicle screw fixation and transforaminal lumbar interbody fusion for L5-S1 isthmic spondylolisthesis. Spine J [epub ahead of print], 2017

43. Uribe JS, Myhre SL, Youssef JA: Preservation or restoration of segmental and regional spinal lordosis using minimally invasive interbody fusion techniques in degenerative lumbar conditions: a literature review. Spine (Phila Pa 1976) 41 (Suppl 8):S50-S58, 2016

44. Wang H, Zhou Y, Zhang Z: Postoperative dysesthesia in minimally invasive transforaminal lumbar interbody fusion: a report of five cases. Eur Spine J 25:1595-1600, 2016

45. Wang J, Zhou Y: Perioperative complications related to minimally invasive transforaminal lumbar fusion: evaluation of 204 operations on lumbar instability at single center. Spine J 14:2078-2084, 2014

46. Wu AM, Chen CH, Shen ZH, Feng ZH, Weng WQ, Li SM, et al: The outcomes of minimally invasive versus open posterior approach spinal fusion in treatment of lumbar spondylolisthesis: the current evidence from prospective comparative studies. BioMed Res Int 2017:8423638, 2017

47. Wu MH, Dubey NK, Li YY, Lee CY, Cheng CC, Shi CS, et al: Comparison of minimally invasive spine surgery using intraoperative computed tomography integrated navigation, fluoroscopy, and conventional open surgery for lumbar spondylolisthesis: a prospective registry-based cohort study. Spine J 17:1082-1090, 2017
48. Yee TJ, Joseph JR, Terman SW, Park P: Expandable vs static cages in transforaminal lumbar interbody fusion: radiographic comparison of segmental and lumbar sagittal angles. Neurosurgery 81:69-74, 2017

\section{Disclosures}

Dr. Chang is a consultant with DePuy Synthes and Globus Medical and has received non-study-related research support from Medtronic.

\section{Author Contributions}

Conception and design: Chang, Massie. Acquisition of data: Chang, Massie, Basheer, Buraimoh. Analysis and interpretation of data: Chang, Massie. Drafting the article: Chang, Massie, Zakaria. Critically revising the article: Chang, Massie, Zakaria. Reviewed submitted version of manuscript: Chang, Massie, Zakaria. Approved the final version of the manuscript on behalf of all authors: Chang. Statistical analysis: Massie, Schultz. Administrative/technical/material support: Chang. Study supervision: Chang.

\section{Correspondence}

Victor Chang: Henry Ford Hospital, Detroit, MI. vchang1@ hfhs.org. 